\title{
THỰC TRẠNG RỐI LOẠN CHỨC NĂNG TUYẾN GIÁP Ở PHỤ NŨ MANG THAI 3 THÁNG ĐÀ̀U TẠI BỆNH VIỆN 19-8
}

Phạm Tuấn Dương, Đặng Thị Hoa

Bệnh viện 19-8, Bộ Công an

DOI: $10.47122 / v j d e .2020 .45 .11$

\section{TÓM TẮT}

Trong thời kỳ mang thai, tuyến giáp thay đổi rõ rệt. Những sự thay đổi này đôi khi là sinh lý, nhưng đôi khi xuất hiện hoặc làm thúc đầy những rối loạn chức năng tuyến giáp( RLCNTG), để lại những hậu quả nặng nề cho cả mẹ và thai nhi nếu không được chẩn đoán và điều trị kịp thời. đặc biệt trong 3 tháng đầu thai kỳ, khi thai nhi chưa tự sản xuất được hormon tuyến giáp mà phụ thuộc hoàn toàn vào mẹ. Trên thế giới đã có nhiều nghiên cứu về vấn đề này, nhưng ở Việt Nam còn rất ít quan tâm. Muc tiêu: Nhận xét thực trạng rối loạn chức năng tuyến giáp ở phụ nữ mang thai trong 3 tháng đầu tại bệnh viện 19-8. Phuơng pháp: Nghiên cứu được tiến hành trên 123 thai phụ mang thai 3 tháng đầu. Các thai phụ được khám lâm sàng, xét nghiệm máu định lượng FT4, TSH, anti-TPO. Kết quả: Dựa trên khoảng tham chiếu khuyến cáo của Hiệp hội tuyến giáp Hoa Kỳ (ATA) 2011 tỷ lệ RLCNTG là 31,7\%. Trong đó, cường giáp $13,0 \%$, suy giáp $16,3 \%$, tình trạng giảm hormon FT4 2,4\%.

Từ khóa: chức năng tuyến giáp, phụ nũ mang thai trong 3 tháng đầu

\section{ABSTRACT \\ Review on the dysfunction of thyroid hormones in pregnant women in the first trimester \\ Pham Tuan Duong, Dang Thi Hoa \\ 19-8 Hospital, Ministry of Public Security}

During pregnancy, the thyroid gland changes markedly. These changes are sometimes physiological, but sometimes appear or promote thyroid dysfunction (ED), with devastating consequences for both mother and fetus if undiagnosed and prompt treatment. Especially in the first 3 months of pregnancy, when the fetus cannot produce thyroid hormones by itself but depends entirely on the mother. In the world there have been many studies on this issue, but in Vietnam there is still very little int. Objective: Comment on the state of thyroid dysfunction in pregnant women in the first 3 months at the Hospital 198. Methods: The study was conducted on 123 first trimester pregnant women. Pregnant women are examined clinically, and have a blood test to determine FT4, TSH, and antiTPO. Results: The overall incidence of thyroid dysfuntion was $31.7 \%$ base on ATA's reference (2011) including hyperthyroidism (13.0\%), hypothyroidism (16.3\%), hypothyroxinemia (2.4\%).

Key words: function of thyroid hormones, pregnant women in the first trimester

Chịu trách nhiệm chính: Phạm Tuấn Dương

Ngày nhận bài: 5/1/2021

Ngày phản biện khoa học: 11/1/2021

Ngày duyệt bài: 4/3/2021

Email: duongbs198@gmail.com

Điên thoại: 0982017105

\section{1. ĐẠT VẤN ĐỀ}

Tuyến giáp có vai trò then chốt trong điều hòa chuyển hóa và phát triển thần kinh của cơ thể. Thời kỳ mang thai, tuyến giáp có thay đổi sinh lý, nhưng cũng xuất hiện hoặc thúc đẩy những RLCNTG gây hậu quả nặng nề cho cả mẹ và thai nhi nếu không được chẩn đoán và điều trị kịp thời. Đặc biệt trong 3 tháng đầu, thai nhi chưa tự sản xuất được hormon tuyến giáp nên phụ thuộc hoàn toàn vào lượng hormon của mẹ qua rau thai. Nếu suy giáp xảy ra trong giai đoạn sớm của thai kỳ có thể gây hại cho sự phát triển não bộ thai nhi, dẫn đến chậm phát triển trí tuệ của đứa trẻ về sau. Việc phát hiện sớm các RLCNTG ở phụ nữ mang thai 3 tháng đầu là 
cần thiết. Những rối loạn trong thời kỳ này thường kín đáo do triệu chứng bị che lấp bởi các triệu chứng của thai nghén nên cần được chẩn đoán bằng các biện pháp cận lâm sàng. Để tránh sai sót trong chẩn đoán, cần đối chiếu nồng độ hormon với các khoảng tham chiếu khuyến cáo dành cho đối tượng mang thai, theo từng giai đoạn của thai kỳ.

Bên cạnh việc thay đổi các hormon tuyến giáp, tình trạng tự kháng thể kháng giáp dương tính gặp khá phổ biến, khoảng $10-20 \%$ phụ nữ mang thai ở 3 tháng đầu. Dù chức năng tuyến giáp vẫn bình thường, tình trạng này vẫn độc lập làm tăng nguy cơ sảy thai lên gấp 3,73 lần, làm tăng tỷ lệ nạo phá thai, vô sinh, sinh non và kém đáp ứng thụ tinh trong ống nghiệm... Việt Nam hiện có ít nghiên cứu về RLCNTG trong thai kỳ, vì vậy chúng tôi tiến hành nghiên cứu với mục tiêu: "Nhận xét thực trạng rối loạn chức năng tuyến giáp ở phu nũ mang thai trong 3 tháng đầu tại bệnh viện 19-8”.

\section{2. ĐỐI TƯợNG VÀ PHƯƠNG PHÁP NGHIÊN CÚ'U}

\section{1. Đối tượng nghiên cứu}

Đối tượng nghiên cứu là 123 phụ nữ mang

Bảng 1. Khoảng tham chiếu TSH, FT4 của phụ nữ mang thai 3 tháng đầu

\begin{tabular}{|c|c|c|}
\hline & Khoảng tham chiếu & Tiêu chuẩn \\
\hline TSH $(\mathrm{mIU} / \mathrm{l})$ & $0,1-2,5$ & ATA 2011 [1] \\
\hline FT4 $(\mathrm{pmol} / \mathrm{l})$ & $9-24$ & Máy xét nghiệm abbott \\
\hline
\end{tabular}

Xét nghiệm FT4 tại khoa hoá sinh bệnh viện 19-8 qua hệ thống Architect iSystem của hãng Abbott. Kháng thể anti-TPO được xác định là dương tính khi nồng độ $\geq 5,61 \mathrm{IU} / \mathrm{ml}$ theo khuyến cáo của hãng abbott.

\subsection{2. Đánh giá và so sánh:}

* Theo tiêu chuẩn của ATA 2011 [1], vì đây là tiêu chuẩn mới và rõ ràng nhất về hướng dẫn chẩn đoán các RLCNTG dành riêng cho phụ nữ trong thời kỳ mang thai và sau sinh. Hiệp hội bao gồm các chuyên gia đại diện từ các hiệp hội khắp các châu lục (ATA, Hiệp hội tuyến giáp Châu Á - Thái Bình Dương (AOTA), Hiệp Hội thai dưới 14 tuần đến khám tại phòng khám khoa Nội tiết - ĐTĐ - Bệnh viện 19-8 và phòng khám Sản - bệnh viện 19-8, từ tháng 11 năm 2019 đến tháng 10 năm 2020.

\subsubsection{Tiêu chuẩn lựa chọn :}

+ Phụ nữ mang đơn thai, thụ thai tự nhiên, thai sống, tuổi thai đến hết 13 tuần.

+ Đồng ý tham gia nghiên cứu

\subsubsection{Tiêu chuẩn loại trù̀:}

+ Thụ thai nhờ các biện pháp hỗ trợ sinh sản: IUI, IVF.

+ Đang sử dụng các thuốc ảnh hưởng đến kết quả xét nghiệm như: hormon tuyến giáp, kháng giáp trạng, amiodarone, lithium, các chế phẩm corticoid, hormon sinh dục (estrogen).

+ Đang mắc các bệnh cấp tính: nhiễm khuẩn, lao phổi, suy gan, suy thận.

+ Các thai phụ không đồng ý tham gia nghiên cứu.

2.2. Phương pháp nghiên cứu: mô tả cắt ngang.

\section{2..1. Thu thập số liệu}

Tất cả các đối tượng nghiên cứu được khám, lấy máu xét nghiệm nồng độ $\mathrm{FT}_{4}$, TSH, anti- TPO tại khoa Hoá sinh BV 19-8. tuyến giáp Châu Mỹ Lating (LATS), Hiệp Hội các nhà sản phụ khoa Hoa Kỳ (ACOG). Đồng thời hướng dẫn của ATA cũng được đồng thuận Hiệp Hội các nhà Nội tiết Lâm sàng Hoa Kỳ (AACE), Hiệp Hội nội tiết Hoa Kỳ (AES) trong các hướng dẫn lâm sàng.

\section{Chẩn đoán suy giáp:}

- Suy giáp lâm sàng được xác định trong 2 trường hợp sau:

+ Nồng độ TSH $\geq 10$ mIU /1.

$+2,5 \mathrm{mIU} / 1<\mathrm{TSH}<10 \mathrm{mIU} / 1$ và nồng độ FT4 $<9$ pmol/1

- Suy giáp dưới lâm sàng được xác định khi 
TSH từ 2,5- 10 mIU/1 và nồng độ FT4 trong giới hạn bình thường.

\section{Chẩn đoán cường giáp:}

- Cường giáp lâm sàng được xác định khi định lượng nồng độ $\mathrm{TSH}<0,1 \mathrm{mIU} / 1$ và nồng độ FT4 cao (> 24 pmol/1).

- Cường giáp dưới lâm sàng được xác định khi nồng độ $\mathrm{TSH}<0,1 \mathrm{mIU} / 1$ và nồng độ FT4 trong giới hạn bình thường (từ 9,0-24,0 mIU/l).

\section{Chẩn đoán tình trạng giảm hormon}

FT4 khi TSH bình thường (từ $0,1-2,5 \mathrm{mIU} / \mathrm{l}$ ) và nồng độ FT4 giảm $(<9,0$ pmol/l).

Rối loạn chức năng tuyến giáp thai kỳ:

Thai phụ được xác định là có RLCNTG khi được chẩn đoán 1 trong 3 rối loạn sau: suy giáp, cường giáp, tình trạng giảm FT4.

2.2.3. Xử lý số liệu: Phần mềm SPSS 16.0.

\section{KẾT QUẢ NGHIÊN CỨU}

\section{1. Đặc điểm chung của nhóm nghiên cứu}

Bảng 2. Đặc điểm chung của nhóm nghiên cứu

\begin{tabular}{|l|c|c|c|}
\hline \multicolumn{1}{|c|}{ Đặc điểm } & TB \pm SD & Min & Max \\
\hline Tuổi & $30,52 \pm 4,73$ & 19 & 39 \\
\hline Tuần thai (tuần) & $10,43 \pm 2,8$ & 4 & 13 \\
\hline BMI $\left(\mathrm{kg} / \mathrm{m}^{2}\right)$ & $20,89 \pm 2,12$ & 16,18 & 27,34 \\
\hline
\end{tabular}

Nhận xét: Các đối tượng trong nghiên cứu của chúng tôi có tuổi trung bình là 30,52; với tuần thai trung bình 10 tuần. Không có thai phụ nào có $B M I \geq 40 \mathrm{~kg} / \mathrm{m}^{2}$.

3.2. Các rối loạn chức năng tuyến giáp

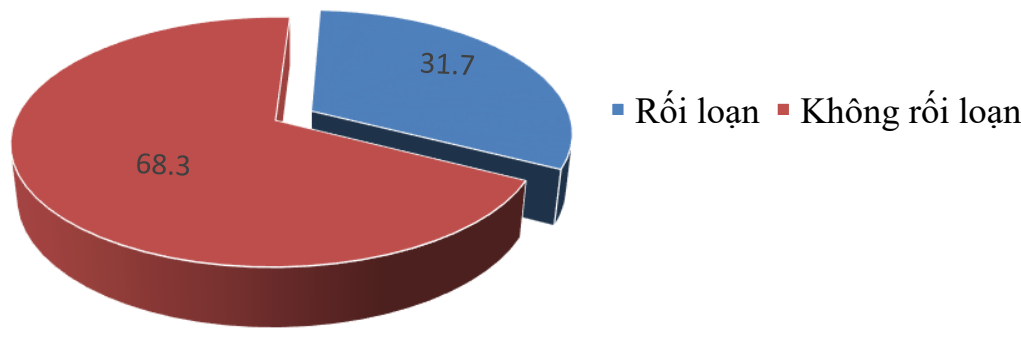

Biểu đồ 1. Tỷ lệ các rối loạn chức năng tuyến giáp

Nhận xét: Có 31,7\% số thai phụ trong nghiên cứu bị các RLCNTG. Tỷ lệ các thai phụ không bị RLCNTG là $68,3 \%$.

Bảng 3. Các rối loạn chức năng tuyến giáp

\begin{tabular}{|l|l|c|c|c|}
\hline \multicolumn{2}{|c|}{ Các rối loạn } & \multicolumn{2}{c|}{ T } & Tỷ lệ (\%) \\
\hline \multirow{2}{*}{ Suy giáp } & Lâm sàng & 9 & \multirow{2}{*}{20} & \multirow{2}{*}{$\mathbf{1 6 , 3}$} \\
\cline { 2 - 3 } & Dưới lâm sàng & 11 & & \multirow{2}{*}{16} \\
\hline \multirow{2}{*}{ Cường giáp } & Lâm sàng & 3 & 13 \\
\cline { 2 - 3 } & Dưới lâm sàng & 13 & & \\
\hline
\end{tabular}




\begin{tabular}{|c|c|c|}
\hline Tình trạng giảm hormon FT4 & 3 & $\mathbf{2 , 4}$ \\
\hline Bình giáp & 84 & $\mathbf{6 8 , 3}$ \\
\hline Tổng & 123 & $\mathbf{1 0 0}$ \\
\hline
\end{tabular}

Nhận xét: Các rối loạn chức năng tuyến giáp ở các thai phụ trong nghiên cứu bao gồm: 20 người bị suy giáp $(16,3 \%), 16$ người bị cường giáp $(13,0 \%)$ và 3 người $(2,4 \%)$ có tình trạng tình trạng giảm hormon FT4. Trong nhóm nghiên cứu có 84 thai phụ có chức năng tuyến giáp bình thường, chiếm $68,3 \%$.

\section{BÀN LUẬN}

\subsection{Rối loạn chức năng tuyến giáp}

Tình trạng rối loạn chức năng tuyến giáp ở phụ nữ mang thai là khá phổ biến. Tỷ lệ này khác nhau giữa các quốc gia, phụ thuộc vào tiêu chuẩn chẩn đoán, đặc điểm dân cư, dinh dưỡng và chế độ chăm sóc y tế [1].

Các rối loạn chức năng tuyến giáp ở các thai phụ trong nghiên cứu bao gồm: 20 người bị suy giáp $(16,3 \%), 16$ người bị cường giáp $(13,0 \%)$ và 3 người $(2,4 \%)$ có tình trạng tình trạng giảm hormon FT4. Trong nhóm nghiên cứu có 84 thai phụ có chức năng tuyến giáp bình thường, chiếm $68,3 \%$.

Nghiên cứu có kết quả giống Đỗ Thị Tuyết Nhung năm 2015 có $38,5 \%$ số thai phụ bị các RLCNTG bao gồm: 17 thai phụ bị suy giáp $(10,9 \%), 26$ thai phụ bị cường giáp $(16,7 \%)$ và $17(10,9 \%)$ thai phụ có tình trạng giảm hormon FT4. Trong nhóm nghiên cứu có 96 thai phụ có chức năng tuyến giáp bình thường, chiếm $61,5 \%$ [11]. So sánh với các nghiên cứu trong khu vực Châu Á, chúng tôi thấy kết quả cao hơn với nghiên cứu của tác giả Wang [2], [4], với RLCNTG gặp ở 10,2\% số thai phụ ( cường giáp gặp 1,8\%, suy giáp gặp 7,5\% và tình trạng giảm hormon FT4 là $0,9 \%$ ), cũng cao hơn Dinesh (Ấn Độ), RLCNTG gặp ở 15,5\% thai phụ với các tỷ lệ tương ứng là $0,3 \%, 14,3 \%$ [13].

\subsection{Suy giáp}

Suy giáp là bệnh lý hay gặp thứ hai trong thời kỳ mang thai, chỉ sau ĐTĐ thai kỳ. Suy giáp dù là suy giáp lâm sàng hay dưới lâm sàng đều có bằng chứng gây ra các kết cục không tốt cho mẹ và thai nhi. Việc điều trị suy giáp có thể cải thiện các kết cục này, và giúp cho các bà mẹ có một thai kỳ bình thường và hạnh phúc hơn nữa là có những đứa con khỏe mạnh. Theo tiêu chuẩn của ATA 2011, trong nghiên cứu chúng tôi có 20 thai phụ (chiếm 16,3\%) được chẩn đoán là suy giáp; trong đó có 9 thai phụ chẩn đoán suy giáp lâm sàng $(7,31 \%)$ và 11 thai phụ được chẩn đoán suy giáp dưới lâm sàng $(8,94 \%)$.

Kết quả chúng Tôi giống nghiên Đỗ Thị Tuyết Nhung theo cùng tiêu chuẩn có 17 thai phụ (chiếm 10,9\%) được chẩn đoán là suy giáp; trong đó có 4 thai phụ chẩn đoán suy giáp lâm sàng $(2,6 \%)$ và 13 thai phụ được chẩn đoán suy giáp dưới lâm sàng $(8,3 \%)$ [11].

Tác giả Đỗ Thị Thu Thuỷ sử dụng tiêu chuẩn dành cho phụ nữ không mang thai ( lấy $\mathrm{TSH}>4,2 \mathrm{mlU} / \mathrm{l}$ ) thì có 58/2100 thai phụ bị suy giáp ( chiếm $2,8 \%$ ); trong đó suy giáp lâm sàng là $0,8 \%$ và suy giáp dưới lâm sàng là $2 \%$ [10]. Có thể thấy tỷ lệ này thấp hơn nhiều so nghiên cứu chúng tôi.

Việt Nam chưa có nhiều nghiên cứu tỷ lệ suy giáp trong thai kì theo tiêu chuẩn chẩn đoán của ATA 2011. Trên thế giới, tỷ lệ này cũng chênh lệch giữa các nghiên cứu của các tác giả khác nhau, tùy thuộc vào cách áp dụng khoảng tham chiếu của TSH. Ở Trung Quốc, nghiên cứu của Yang lấy giới hạn trên của TSH là $3,47 \mathrm{mIU} / 1$ thì tỷ lệ suy giáp gặp 4,4\%. Còn tỷ lệ này trong nghiên cứu của Wang là $7,5 \%$ [8]. Tác giả Li nghiên cứu 4800 phụ nữ Trung Quốc mang thai kỳ đầu thấy tỷ lệ suy giáp dưới lâm sàng khá cao $(27,8 \%)$ nếu sử dụng tiêu chuẩn chẩn đoán của ATA 2011 [14].

Tỷ lệ suy giáp của chúng tôi khá lớn so với báo cáo trước đây khi áp dụng tiêu chuẩn cũ cho người không mang thai thì tỷ lệ thai phụ được xếp vào nhóm suy giáp ở nghiên cứu của chúng tôi tăng lên nhiều. Do đó, một số lượng lớn hơn các thai phụ sẽ được chẩn đoán sớm và được hưởng chế độ chăm sóc thai sản chu đáo hơn. Qua đó góp phần giảm bớt các tai biến không mong muốn trong thai kỳ[15], [16]. 


\subsection{Cường giáp}

Cường giáp trong thời kỳ mang thai hay gặp trong 3 tháng đầu thai kỳ. Có 2 nguyên nhân hay gặp nhất là cường giáp thoáng qua do thai nghén và cường giáp do bệnh Basedow.

Nghiên cứu của chúng tôi có $16 / 123$ thai phụ bị cường giáp, chiếm $13,0 \%$, trong đó chủ yếu là cường giáp dưới lâm sàng $(10,6 \%)$, cường giáp lâm sàng $2,4 \%$. Tỷ lệ này rất cao so với các báo cáo trên thế giới. Nghiên cứu của Đỗ Thị Tuyết Nhung có 26/156 thai phụ bị cường giáp, chiếm $16,7 \%$, trong đó chủ yếu là cường giáp dưới lâm sàng $(13,46 \%)$, cường giáp lâm sàng $3,2 \%$ [11].

Việt Nam có ít các nghiên cứu báo cáo tỷ lệ cường giáp trong thời kỳ mang thai. Tác giả Nguyễn Hải Thủy gặp từ 0,1 đến $1,0 \%$ cường giáp do bệnh Basedow và $1-3 \%$ cường giáp do thai nghén [12] Tác giả Trương Đình Tá không gặp thai phụ nào trong 3 tháng đầu có $\mathrm{TSH}<0,1$ $\mathrm{mIU} / 1$ trong tổng số 30 thai phụ nghiên cứu [9]. Tác giả Lê Thị Mai Dung báo cáo có $6,76 \%$ trường hợp $\mathrm{TSH}<0,1 \mathrm{mIU} / 1(\mathrm{n}=133)$.

Ở Trung Quốc, tác giả Wang gặp 1,8\% số thai phụ trong thời kì mang thai 3 tháng đầu có $\mathrm{TSH}<0,13 \mathrm{mIU} / 1$ được chẩn đoán là cường giáp (lâm sàng và dưới lâm sàng), tác giả Yang có $1,0 \% \mathrm{TSH}<0,09 \mathrm{mIU} / 1$ được chẩn đoán là cường giáp trong thời kỳ mang thai 3 tháng đầu $(0,5 \%$ cường giáp lâm sàng và $0,5 \%$ cường giáp dưới lâm sàng) [2].

Như vậy, tỷ lệ cường giáp của chúng tôi khác với các tác giả khác chủ yếu là ở nhóm cường giáp dưới lâm sàng. Tỷ lệ này ở nghiên cứu của chúng tôi khá cao. Tuy nhiên, nhiều tác giả nhận định cường giáp dưới lâm sàng không liên quan đến các biến cố thai sản mà chủ yếu liên quan đến cường giáp thai nghén thoáng qua [1]. Để có thể chẩn đoán rõ ràng hơn chúng tôi cần có các xét nghiện sâu hơn như TRAb, $\beta$-hCG mới có thể nhận định được. Bên cạnh đó, do địa điểm lấy mầu nghiên cứu tại các phòng khám Nội tiết và Sản khoa. Tỷ lệ này ở cộng đồng sẽ lớn hơn nhiều do tâm lý thai phụ chỉ đi khám khi bản thân họ có bệnh lý tuyến giáp từ trước, triệu chứng lâm sàng khó chịu hoặc có yếu tố nguy cơ nào đó. Như chúng tôi thống kê ở trên, tỷ lệ thai phụ có các yếu tố nguy cơ là khá cao. Do đó, tỷ lệ bệnh lý mà chúng tôi thu được chỉ đại diện cho quần thể thai phụ đến khám bệnh. Tỷ lệ này sẽ cao hơn nếu ở cộng đồng. Để có cái nhìn tổng quan về rối loạn chức năng tuyến giáp thai kỳ ở Việt Nam, cần tiến hành các nghiên cứu lớn hơn và rộng khắp tại cộng đồng.

\subsection{Tình trang giảm FT4}

Đây là tình trạng thiếu hormon tuyến giáp thường liên quan đến iod. Một vài nghiên cứu cho rằng tình trạng giảm hormon FT4 ít có liên quan đến các kết cục bất lợi trong thai kỳ [3]. Tuy nhiên tình trạng này ảnh hưởng đến sự hình thành hệ thần kinh của thai nhi và phát triển tâm thần kinh của trẻ về sau [10], [12].

Trong 123 thai phụ tham gia nghiên cứu, chúng tôi thấy có 3 thai phụ (chiếm 2,4\%) có mức FT4 dưới 9,0 pmol/1 đồng thời mức TSH trong giới hạn bình thường, được chẩn đoán là có tình trạng giảm hormon FT4. Tỷ lệ này trong nghiên cứu của Wang [2] là $1,3 \%$ và của Yang [8] là $0,9 \%$.

\section{KẾT LUẦN}

Tỷ lệ rối loạn chức năng tuyến giáp ở phụ nữ trong thời kỳ mang thai là khá lớn. Cần tầm soát để kịp thời phát hiện và điều trị nhằm giảm thiểu các biến chứng cho mẹ và con.

\section{TÀI LIÊUU THAM KHẢO}

1. Stagnaro-Green A và et al (2011), "Guidelines of the American Thyroid Association for the Diagnosis and Management of Thyroid Disease During Pregnancy and Postpartum", Thyroid.

2. Wang $\mathrm{W}$ và et al (2011), "The prevalence of thyroid disorders during early pregnancy in China: the benefits of universal screening in the first trimester of pregnancy", Eur $J$ Endocrinol, tr. 164(2):263-8.

3. Negro $R$ và et al (2010), "Increased pregnancy loss rate in thyroid antibody negative women with TSH levels between 
2.5 and 5.0 in the first trimester of pregnancy", J Clin Endocrinol Metab, 95, tr. 44-48.

4. Glinoer D (2003), "Management of hypoand hyperthyroidism during pregnancy", Growth horm IGF Res, 13A, tr. 45-54.

5. Yang $H$ và et al (2014), "Screening Strategies for thyroid disorder in the first and second trimester of pregnancy in China", Plos One, 12(9), tr. 6- 12.

6. Trương Đình Tá (2009), "Nghiên cứu tỷ lệ bất thường nồng độ TSH và TPO-ab trên phụ nữ mang thai", Luận văn tốt nghiệp Củ nhân kỹ thuật y học, Truờng Đại học Y Hà Nội.

7. Đỗ Thị Thu Thủy và cs (2014), "Nghiên cứu ảnh hưởng của suy giáp thai kỳ đến mẹ và thai nhi tại Bệnh viện phụ sản Hải Phòng", Tạp chí phu sản, 12(02), tr. 120-122.

8. Đỗ Thị Tuyết Nhung và cs (2015) "Nhận xét nổng độ hormon tuyến giáp, anti-TPO huyết thanh và hình ảnh siêu âm tuyến giáp ở phụ nữ trong 3 tháng đầu thai kỳ" Luận văn Thạc sỹ Y học, Trường Đại học Y Hà Nội.

9. Nguyễn Hải Thủy (2012), "Chẩn đoán và điều trị Cường giáp trong thời kỳ mang thai", Tạp chí phu sản, 10(3), tr. 21-34.

10. Dinesh K, Dhanwal et al (2013), "High prevalence of subclinical hypythyroidism during first trimester of pregnancy in North India", Indian Journal of Endocrinology and Metabolism, 17(2), 281-283.

11. Li C et al (2014), "Assessment of thyroid function during first trimester pregnancy: what is the rational upper limit of serum TSH during the first trimester in Chinese pregnant women?", J Clin Endocrinol Metab, 99(1), 73-79.

12. Abalovich M (2007), "Clinical practice guideline: management of thyroid dysfunction during pregnancy and postpartum: an endocrine society clinical practice guideline", Journal of Clinical Endocrinology and Metabolism, 92(8), S1-S47.

13. Vaidya B et al (2007), "Detection of thyroid dysfunction in early pregnancy: Universal screening or targeted high-risk case finding?", J Clin Endocrinol Metab, 92(1), 203-7. 